\title{
Diffuse myocardial fibrosis is associated with impaired myocardial strain and disease activity in rheumatoid arthritis: a cardiovascular magnetic resonance study
}

\author{
Ntobeko A Ntusi ${ }^{1 *}$, Stefan K Piechnik ${ }^{1}$, Jane M Francis ${ }^{1}$, Vanessa M Ferreira ${ }^{1}$, Paul M Matthews ${ }^{2,3}$, \\ Matthew D Robson ${ }^{1}$, Paul B Wordsworth ${ }^{4}$, Stefan Neubauer ${ }^{1}$, Theodoros D Karamitsos ${ }^{1}$
}

From 17th Annual SCMR Scientific Sessions

New Orleans, LA, USA. 16-19 January 2014

\section{Background}

Rheumatoid arthritis (RA) is a chronic autoimmune disease of the joints, with frequent extra-articular complications including cardiovascular disease and cardiac fibrosis from multiple causes. Diffuse myocardial fibrosis can be detected non-invasively by extracellular volume (ECV) mapping based on pre- and postcontrast T1 measurements using cardiovascular magnetic resonance (CMR). We therefore hypothesized that CMR T1 mapping can detect subclinical diffuse myocardial fibrosis in patients with RA.

\section{Methods}

39 RA patients ( 28 female, mean age $50 \pm 12$ years) and 39 matched controls ( 28 female, mean age $49 \pm 12$ years) without previously known cardiovascular disease underwent CMR at 1.5T. CMR assessments included late gadolinium enhancement (LGE) [IV gadoterate meglumine at $0.15 \mathrm{mmol} / \mathrm{kg}$, T1 mapping, cine, tagging, and T2-weighted imaging.

\section{Results}

Focal fibrosis on LGE was found in 18 (46\%) RA patients compared to none of controls. Two of these patients had evidence of subendocardial enhancement, in keeping with previously unknown myocardial infarction. Evidence of diffuse myocardial fibrosis in RA was supported by higher precontrast T1 values $(973 \pm 27$ vs.

'Division of Cardiovascular Medicine, Radcliffe Department of Medicine, University of Oxford \& John Radcliffe Hospital, Oxford, UK Full list of author information is available at the end of the article
$961 \pm 18 \mathrm{~ms}, \mathrm{p}=0.03)$, lower postcontrast $\mathrm{T} 1$ values $(450 \pm 40$ vs. $468 \pm 32 \mathrm{~ms}, \mathrm{p}=0.04)$ and expansion of ECV $(30.3 \pm 3.4$ vs. $27.9 \pm 2.0 \%, \mathrm{p}<0.001)-$ the 2 RA patients with MI were excluded from this analysis. Indices of diffuse myocardial fibrosis were significantly elevated in RA, regardless of the presence of LGE. There was no difference in left ventricular volumes, mass and ejection fraction between RA patients and controls. However, there were differences in regional function: peak systolic circumferential strain $(-16.9 \pm 1.3$ vs. $-18.7 \pm 1.2, \mathrm{p}<0.001)$ and peak diastolic strain rate $(83 \pm 21$ vs. $112 \pm 20 \mathrm{~s}-1, \mathrm{p}<0.001)$ were impaired in RA patients. Indices of diffuse myocardial fibrosis correlated with impaired myocardial systolic strain, diastolic strain rate and RA disease activity. There was no evidence of myocardial edema in RA.

\section{Conclusions}

Cardiac involvement is common in RA patients with no cardiovascular symptoms, and includes both focal and diffuse myocardial fibrosis, which is associated with impaired systolic and diastolic strain parameters, as well RA disease activity. CMR is a robust non-invasive tool for the assessment of diffuse myocardial fibrosis, and may be useful in the follow-up of patients. Alterations in diffuse myocardial fibrosis likely precede significant changes in cardiac structure and function.

\section{Funding}

This study was funded by an investigator-led grant from GSK to Dr. Theo Karamitsos. The authors gratefully 
Table 1 Baseline characteristics and CMR findings

\begin{tabular}{|c|c|c|c|}
\hline & $\begin{array}{c}\text { Controls } \\
\mathrm{N}=39\end{array}$ & $\begin{array}{c}\text { RA } \\
N=39\end{array}$ & $P$ value \\
\hline Female sex, n (\%) & $28(72)$ & $28(72)$ & 1.00 \\
\hline Age, years & $49 \pm 12$ & $50 \pm 12$ & 0.65 \\
\hline Hypertension, n (\%) & $2(5)$ & $5(13)$ & 0.65 \\
\hline Diabetes, n (\%) & 0 & $1(3)$ & - \\
\hline Hyperlipidaemia, n (\%) & $5(13)$ & $6(15)$ & 0.75 \\
\hline $\mathrm{BMI}, \mathrm{kg} / \mathrm{m} 2$ & $24 \pm 4$ & $26 \pm 5$ & 0.13 \\
\hline DAS28-CRP (median, IQR) & N/A & $3.3 \pm 1.3$ & - \\
\hline ESR, mm/hr (median, IQR) & N/A & $15(9-19)$ & - \\
\hline CRP, mg/L (median, IQR) & $1(1-2)$ & $9(4-13)$ & $<0.001$ \\
\hline Hemoglobin, g/L & $13 \pm 1$ & $13 \pm 1$ & 0.47 \\
\hline Duration of RA, years (median, IRQ) & N/A & $7(4-11)$ & - \\
\hline Duration of DMARDs, years (median, IQR) & N/A & $4(3-6)$ & - \\
\hline LVEDV indexed to BSA, $\mathrm{ml} / \mathrm{m} 2$ & $78 \pm 15$ & $80 \pm 16$ & 0.63 \\
\hline LVESV indexed to BSA, $\mathrm{ml} / \mathrm{m} 2$ & $24 \pm 16$ & $23 \pm 9$ & 0.62 \\
\hline LVEF, \% & $73 \pm 5$ & $72 \pm 7$ & 0.25 \\
\hline LV Mass indexed to BSA, g/m2 & $52 \pm 11$ & $54 \pm 12$ & 0.34 \\
\hline LA size, $\mathrm{mm}$ & $27 \pm 5$ & $32 \pm 5$ & $<0.001$ \\
\hline Mid SA circumferential strain & $-19.0 \pm 1.2$ & $-17.1 \pm 1.2$ & $<0.001$ \\
\hline Peak diastolic circumferential strain rate $(s-1)$ & $117 \pm 18$ & $85 \pm 18$ & $<0.001$ \\
\hline Presence of LGE (\%) & 0 & $18(46)$ & - \\
\hline Volume fraction of LGE > 2SD (\%) & 0 & $3.7 \pm 0.4$ & - \\
\hline STIR T2 Ratio & $1.5 \pm 0.1$ & $1.6 \pm 0.2$ & 0.07 \\
\hline
\end{tabular}

Continuous data are mean \pm SD unless otherwise indicated. BMI, body mass index; CRP, C-reactive protein; DMARD, disease modifying anti-rheumatic drug; ESR, erythrocyte sedimentation rate; IQR, interquartile range; LA, left atrium; LGE, late gadolinium enhancement; LV, left ventricle/ventricular; LVEDV, left ventricular end-diastolic volume; LVEF, left ventricular ejection fraction; LVESV, left ventricular end-systolic volume; RA, rheumatoid arthritis; SA, short axis; STIR, short Tau inversion recovery

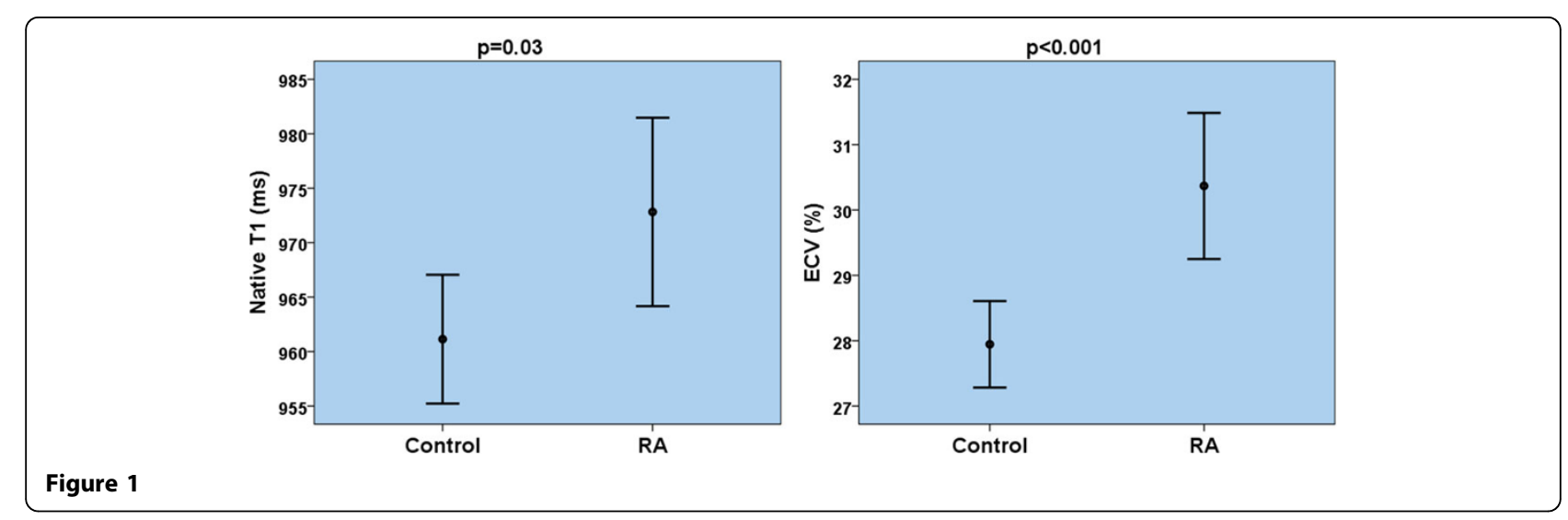

acknowledge support from the National Institute for Health Research Oxford Biomedical Research Centre Programme. Prof. Stefan Neubauer also acknowledges support from the Oxford British Heart Foundation Centre for Research Excellence.

\section{Authors' details}

${ }^{1}$ Division of Cardiovascular Medicine, Radcliffe Department of Medicine, University of Oxford \& John Radcliffe Hospital, Oxford, UK. ${ }^{2}$ GlaxoSmithKline Clinical Imaging Centre, GlaxoSmithKline, London, UK. 'Division of Brain Sciences, Department of Medicine, Imperial College, London, UK. ${ }^{4} \mathrm{NIHR}$ Oxford Musculoskeletal Biomedical Research Unit \& Nuffield Department of 
Orthopaedics, Rheumatology and Musculoskeletal Sciences, University of Oxford \& Nuffield Orthopaedic Centre \& John Radcliffe Hospital, Oxford, UK.

Published: 16 January 2014

doi:10.1186/1532-429X-16-S1-P292

Cite this article as: Ntusi et al.: Diffuse myocardial fibrosis is associated with impaired myocardial strain and disease activity in rheumatoid arthritis: a cardiovascular magnetic resonance study. Journal of

Cardiovascular Magnetic Resonance 2014 16(Suppl 1):P292.

Submit your next manuscript to BioMed Central and take full advantage of:

- Convenient online submission

- Thorough peer review

- No space constraints or color figure charges

- Immediate publication on acceptance

- Inclusion in PubMed, CAS, Scopus and Google Scholar

- Research which is freely available for redistribution

Submit your manuscript at www.biomedcentral.com/submit
() Biomed Central 